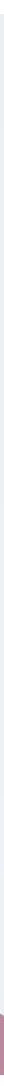

\section{Which perinatal exposures confer a risk of offspring depression?}

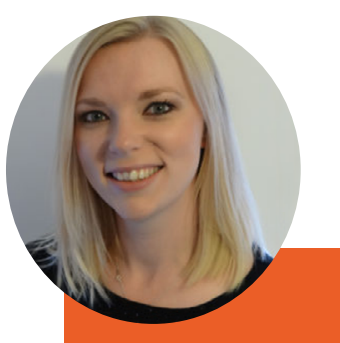

\section{Dr Jessica Edwards}

Jessica is a freelance editor and science writer, and has been writing for the Bridge since December 2017.
In December 2020, the Journal of Child Psychology and Psychiatry published a Research Review authored by Xiangfei Meng and colleagues Yingying Su and Carl D'Arcy on the developmental origins of depression. They focused on exposures in the perinatal period, which includes pregnancy and the first year after birth. We asked the authors to comment on the background to their study, and their main findings from their systematic review and meta-analysis.

"Early life experiences play a profound role in physical and psychological development and health", says Meng. "In addition, in-utero and perinatal adverse exposures can be biologically embedded via epigenetic changes that can impact on mental health in adolescence and later in adulthood through cellular aging. The literature has consistently shown that some of these adverse childhood experiences lead to adulthood mental disorders, but that evidence has not been comprehensively evaluated and summarized. In our study, we used a multifactorial bio-psycho-social model of in-utero, perinatal conditions to articulate the associations 


\begin{tabular}{|c|c|c|}
\hline Biological & Psychological & Sociological \\
\hline $\begin{array}{l}\text { Low birth weight }(<2.5 \mathrm{~kg}) \\
\text { Premature birth }(<37 \text { weeks gestation) } \\
\text { Small for gestational age } \\
\text { Parents' age }<20 \text { years } \\
\text { Parents' age } \geq 35 \text { years }\end{array}$ & $\begin{array}{l}\text { Maternal stress } \\
\text { Maternal anxiety } \\
\text { Maternal prenatal depression }\end{array}$ & $\begin{array}{l}\text { Maternal education ( }<9 \text { years of } \\
\text { study) } \\
\text { Low socioeconomic status } \\
\text { Maternal smoking } \\
\text { Paternal smoking }\end{array}$ \\
\hline
\end{tabular}

Table. Perinatal risk factors significantly associated with risk for depression in offspring.

and causal relationships between early life risk exposures and future mental health".

The authors identified 64 prospective, longitudinal cohort studies that examined the link between 28 perinatal risk exposures and subsequent depression in offspring. In their quantitative analysis, they found that 12 of these factors were significantly associated with an increased risk of offspring depression (Table). These findings provide robust support for the developmental origins of health and disease hypothesisı via a bio-psycho-social model. This hypothesis suggests that the quality of foetal development influences the risk for chronic illness (including mental health problems) over the lifespan.

"While the risk factors identified substantially increase the risk of depression, they are not in themselves necessary and sufficient to cause depression - there are various mitigating and resilient factors that can influence the trajectory from risk exposure to disease", explains Meng.

"However, within a preventative medicine framework, the identification of these early risk factors of depression has important clinical implications as they highlight the need for primary prevention. Pregnancy and the first years of life are critical windows for the development of depression in offspring, so it is an opportune time to intervene to protect against the generation of mental illness in the next generation." Going forward, the researchers hope that prospective studies will be established to investigate the effects of paternal attributes and the combined effect of multiple early life risk exposures.

\section{Referring to:}

Su, Y. et al. (2020), Research Review:

Developmental origins of depression - a

systematic review and meta-analysis.

J. Child Psychol. Psychiatr. doi: 10.1111/

jcpp.13358.

\section{References:}

${ }^{1}$ O'Donnell, K.J. et al. (2017), Fetal origins of mental health: The developmental origins

of health and disease hypothesis. Am. J. Psychiatr. 174,319-328. doi: 10.1176/appi. ajp.2016.16020138.

To visit any of the links related to this article, click here to go to the ACAMH website. 